\title{
Father's Acceptance and Rejection of Children with Disabilities
}

\author{
Natalina Purba ${ }^{1, *}$, Hendra Simanjuntak ${ }^{2}$ \\ ${ }^{1,2}$ Universitas HKBP Nommensen Pematangsiantar \\ ${ }^{*}$ Corresponding author. Email: natalinapurba@aol.com
}

\begin{abstract}
Having children is the most beautiful thing parents will feel everywhere. The dream of many parents is that a child is born with perfection, but what happens when the child that is awaited has limitations? children born with low intellectual abilities or often referred to as mentally retarded children. Gratitude for having a baby is finally accompanied by rejection. Regarding intellectual disabilities children as punishment for past sins. This exploratory study reports some in-depth evidence from the experience of fathers who can ultimately accept the presence of intellectual disabilities children in the family. We conducted in-depth interviews with five fathers who have children with intellectual disabilities. The aim is to describe their experience of fathering a child with special needs. Data were analysed using the Burnard approach, which has similarities with phenomenological and content analysis. Results and discussion show that acceptance of the father with a sincere heart helps the development of mentally retarded children. Initially, there was rejection, because they were ashamed of having a mentally retarded child that the mother took the role of parenting without the support of the father. The father takes the role of parenting after accepting the fact of having an intellectual disabilities child. We conclude that fathers who accept children with intellectual disabilities will share the focus on parenting but the focus is stronger on children with disabilities than other children. Fathers who do not accept their children born with intellectual disabilities will harbour latent anger towards children with disabilities so that the care becomes the mother's own without the father's participation in parenting.
\end{abstract}

Keywords: Parenting, gender, intellectual disabilities, fatherhood.

\section{INTRODUCTION}

Being a father is the dream of a married man, all prayers and hopes are offered for a new-born child, but it will be very different when the child is born with intellectual disabilities. Of course, acceptance and rejection at the beginning of birth often occur in families. In many studies that have been carried out by children born with special needs, they will be cared for by the mother only, without any contribution from the father [1] there have been many studies on the role of mothers towards children with special needs, but no one has focused on parents with children with intellectual disabilities. According to Crnic et, al, most of the research on parents of children with special needs continues to focus on the mother and not on the contributions or experiences of the father [1] plus the specific population of the father of these children with intellectual disabilities has received little attention.

The presence of a child with intellectual disabilities who needs special education and this makes a fundamental change in the family. The joys and joys of a new family turn into failure, despair, emotional confusion, and feelings of inadequacy when the child turns out to be an intellectual disability. Negative thoughts often appear in the father's mind, but all need a process from rejection to acceptance, this process is slow and seems uncertain, but in the end, the father can conquer his selfishness and accept the presence of intellectual disabilities children in his family environment.

There has not been much research on the role of fathers in families with intellectual disabilities, but Hobson and Noyes' research found that in parenting there are fathers who take an active role [2] on the other hand there are fathers who say active roles are difficult, challenging and sometimes stressful especially when the child fell ill [3]. Furthermore, at this time fathers are expected to be able to participate in pregnancy, childbirth, nurturing, caring for, educating children, sharing domestic responsibilities at home, and earning a living [4]. A recent study found that fathers who were actively involved with their children in the early years were more likely to remain engaged throughout their life cycle [5]. Referring to the father, many studies are related to the parents of children, and adults who are having an intellectual disability tends to focus on the mother. In some countries in the world, fathers are only 
tasked with earning a living, which in the end makes mothers feel like they are caring for children who have special needs. However, recent research reveals that fathers' caring practices are not forgotten, but rather develop more slowly because fathers' jobs are breadwinners and their wives or spouses quickly become more 'masters' of childcare because they are unemployed and live at home [6].

The way the father is raised by his parents has also become an experience and a reference for educating his children in the future. Fathers who do not have much time for their children will certainly have a different way of caring for their children in the future than fathers who give attention and love to their children. Previous studies have concluded that men have more power to choose the parameters of their involvement in family life [6]. Speaking of parameters, it is clear that the father has great power for this, especially when the child is born with imperfect or intellectual disabilities, the father is free to choose whether to be involved or not.

In this research, we will examine how their experiences of being a father, with their rejection and acceptance?

\section{METHOD}

There were five fathers invited to the interview who had children with intellectual disabilities, but only three fulfilled the research team's invitation for in-person interviews, two fathers chose to be interviewed by telephone. In this study, we conducted in-depth interviews with five fathers who have intellectual disabilities children. The aim is to describe their experience of fathering a child with special needs. Both acceptance and rejection. data were analysed using the Burnard approach, which has similarities with phenomenological and content analysis.

\subsection{Data Collection}

Face to face interviews using an interview guide which is then recorded. The research team used the research team's knowledge of the literature and experiences of interacting with fathers to develop guidelines. Open-ended questions were used to allow fathers to expand on their personal experiences throughout the interview. Field notes were recorded to contextualize the interview.

\subsection{Respondents}

The research team adopted a purposive sampling strategy and aimed to recruit up to eight fathers in this initial exploratory study. Of the eight fathers, only five fathers fulfilled the invitation of the research team and became respondents.
Table 1. Fathers and number of children in the family

\begin{tabular}{|c|c|}
\hline Father & Number of children \\
\hline UT & 2 \\
\hline AS & 2 \\
\hline GP & 1 \\
\hline SS & 4 \\
\hline JP & 3 \\
\hline
\end{tabular}

In this study the father had children aged eight to eighteen years.

\subsection{Data Analysis}

All steps in data analysis followed the Burnard method, the research team worked on a text-based document, then the text was coded and organized into a meaning unit. This process is iterative, as the research team spends time together developing and refining existing units of meaning. From here the research team analysed the identification of meanings that have been categorized as literal and descriptive. Burnard [8] describes two types of categories: literal categories and descriptive categories [2]. Literal category labels are identified as the literal content of the interview, including the definition and enhancement of problems, such as educational problems [7], [8], [9]. Meanwhile, descriptive category labels were identified as less literal and more geared towards capturing a sense of what respondents said, such as studying the role of fathers at home or difficulties in being a father.

\section{FINDING AND DISCUSSION}

The most important element of the family is the child because the child is a must to continue the lineage. children are also a source of hope and hope for their families. they are important factors for strengthening the institution of marriage. children have a very important role in the family and society; therefore, a healthy offspring is the greatest hope of parents. when children are born imperfect, they will create different perspectives on the family. There are many difficulties faced when children are born with intellectual disabilities, among others, increased economic needs, not having adequate knowledge about the child's condition, changes in the role of family members because of children with disabilities, disorders in marital relationships, unable to participate in social activities due to time constraints or limited funds, or lack of personal time, community attitudes towards children with disabilities and increasing family problems [10]. The family will fight against the stigma of society that intellectual disabilities are a punishment from god, it will be even more painful when the extended family also gives punishment and this will get worse when the child is a boy, where the offspring is male. In many 
ethnic groups in Indonesia, the lineage is male. After a child is diagnosed with an intellectual disability, the family goes through various phases during the process of adapting to the situation. The five fathers we interviewed had different reactions, three fathers are accepted when the child was born with intellectual disabilities and two fathers refused.

\subsection{Rejection}

Denial, two dads: dad feels that this situation can't be real and dad acts to prove this not true. The father tries to gather evidence that it is impossible for his son to have a disability. Furthermore, the family denies the situation and thinks that only the level of performance of the child decreases and forces the child to perform and achieve certain tasks later [11]. Fathers will certainly feel high levels of emotional shock, fear, and stress when their children are diagnosed with intellectual records. This is reinforced by the results of research by Marsh et al [12] ties with children so that the care is owned by the mother itself with all the treatment received from both the husband and other family members. In this situation, the mother will also experience depression because care is the responsibility of the mother [13]. Ignorance and fully surrendering the responsibility for caring to the mother adds to the burden on her psychologically.

The results of the interview proved that the father has not been able to accept the presence of a child with special needs in his family because he continues to think that it is impossible for the child to come from their offspring, and most likely from the mother. When my father leaves his hands, it is certain that he will not take up his role in parenting and this condition remains even during the first two years of questions and doubts about why my child is different from other children.

The reason for the father's rejection is that the family feels like it is heading in an unknown direction. Father felt this was God's punishment and he blamed Mother more when the child was born imperfect. At this point, you are showing symptoms of depression, such as fatigue, hopelessness about the future, you can only cry. With the presence of a disabled child, parents feel like they have reached the end of the ideal child's dream. In depression, parents generally withdraw from their social environment, this is reinforced by the results of research by Beestin et al. Depression is a situation that not only affects the father and mother but also the child is affected [14]. Maybe this is what is often forgotten, a newborn child needs a strong bond with his father and mother, a child needs love from both parents.

It is very different when parents get more detailed information about disabilities, gain insight into how to help their child, and watch their child achieve certain things with the education they receive, their depression is more likely to begin to decrease [15]. At first, my father would feel guilty. Dad would accuse himself of being the cause of the problem. These accusations may also be against one another. This situation generates anger. In this phase, there is latent anger towards the disabled child. Guilt and anger may be on a level that can paralyze family life.

Guilt is the most difficult and intense feeling for a family to overcome. Some parents may feel they are being punished by God for their past mistakes. This will be exacerbated when the families of both parties blame each other. Then latent anger towards the handicapped child is rejected and guilt for normal children is preferred. Parents can even get mad at themselves for feeling guilty and they can get rid of this guilt after a very difficult step. The results of the interview also proved that although the rejection of the child lasted for a long time, ranging from six months to one year to accept the presence of an intellectual disabilities child, none of the fathers who became our respondents wanted to end their marriage or divorce as a way out this was strengthened. With Wieder's research results, when they are no longer able to face this problem, divorce [16] is one of the solutions that couples who have children with special needs will choose.

\subsection{Acceptance}

Accept, three fathers: acceptance is the most important step in embracing a child with disabilities. With the birth of an intellectual disability child, adaptation may be brief for some families, while it may take longer for some. For three fathers who can accept the fact that children born with intellectual disabilities experience more challenges even from their own families. Accusations from family members to other members can influence the father's actions. In this phase, the three fathers we interviewed when the child was born and they accepted the child's presence began to make realistic plans and set realistic expectations. They guide their children to the correct educational program. If they have other children, they also share a strong focus on children with disabilities with other children. Parents started spending more time together. Acceptance is an active situation that requires an understanding of the child's problems and constant efforts to solve these problems. Parents who accept the presence of an intellectually disabled child will experience a fundamental change in their life.

This fundamental change was revealed in interviews with three fathers that, when the results of their children's observations came out and the results were that the children had intellectual disabilities, the first thing they did was to reinforce each other and not blame each other. According to one of the fathers who accepted, it was shocked but impossible not to receive one's flesh and blood. Another father said there was 
nothing else to be done but to accept the child with all its flaws, no need to blame each other because all this would add to the list of hurt feelings on both sides.

The crisis period ends in acceptance. During this period, parents began to think in a more realistic way about how to help their children. Parents, accepting their situation with childbirth, showed faster progress by sharing care tasks. For families who have accepted children with special needs are ready to embrace their children as they are. However, this point also should not be overlooked the fact that life will not be as easy for families who share emotions and are responsible in solving their children's problems as well.

During the interview, the father said that anxiety also arises on special days, such as birthdays, or holidays, religious holidays it will be very difficult for parents to participate in these celebrations. Even families, who study their children's diagnoses early on and go through phases of acceptance can revive their problems in certain cases, such as when the child reaches school age [13]. This means that when children are born with special needs, parents must prepare themselves to educate, raise, and accompany their children in the most difficult times of their lives.

We also found that allowing intellectual disabilities children to grow and develop, means framing a future for them with all the hopes that have been made on them means also preparing parents to accompany the children during their growth and development. This community seems that they need a forum so that they can share information on how to educate and raise children with all their special needs.

\subsection{Father's Involvement in Parenting}

The birth of a child with different characteristics when expecting a normal child, and all the expectations and plans established for the child to be born can result in drastic changes in the social environment, hopes, plans, and ideals, as well as the economic condition of the family. In families who have difficulty coping with the situation, fathers who see themselves as directly responsible for economic problems can reject their children. [16], but other research shows that working fathers can still spend more time with their children than fathers who do not have disabled children [17]. The father has to decide as to whether or not to take up the parenting role.

On the other hand, fathers will make a significant contribution to the social, emotional, and cognitive development of their children if the children are born normal [18], but often ignore intellectual disabilities, the involvement of fathers in the lives of their children, children aged schools have higher academic performance, exhibit better imitation skills, and show signs of healthier emotional development [19]. In adolescence, the father-son relationship has a significant impact on behaviour [20] when fathers are involved in parenting. Then the bond between father and son will be closely intertwined so that this will significantly influence the child's life and socio-emotional development.

The impact of a father's acceptance or rejection of children with special needs is felt through his close family and extended family and thus greatly affects the welfare of the child [21], [22] acceptance of a child with disabilities will certainly affect the child's survival. Children have feelings and the child will feel that if he is not wanted it will have an impact on the child's character, they will look for various ways to be noticed, sometimes they will do something extreme too, but when the love of the father and mother fills his life, he will feel happier, social development and emotionally better.

Although fathers seem confident in their acceptance of intellectually disabled children, they still seem less certain about their immediate future role. Three fathers expressed uncertainty about raising their child, especially in the first few weeks, and this often-caused anxiety that there was not a community for parents with children with intellectual disabilities or other disabilities. The anxiety of being a father with special needs was strengthened by the results of research by Chin and his friends [3]. Martins and his friends revealed that in their research, fathers with intellectual disabilities would have more negative emotions than positive emotions [23], it is often mothers and children who will be the targets of these negative emotions, this is reinforced by the results of Heiman's research [24]. The negative side is such as frustration, guilt, hurt especially when comparing it with other people's children.

The results of a study in the United States showed that fathers were more likely to be depressed at birth and the results showed that $68 \%$ of fathers experienced depression during the first five years of being a father [25]. In this study, three fathers realized that the child who was born was his flesh and blood and it was not the child's fault to be born like that and also not a punishment from God, this was one of God's ways to reveal His greatness. Two fathers refuse and think that none of their offspring are like that and are always looking for loopholes and ways to hurt each other and according to the five fathers we interviewed, thirdperson interference in this case family and neighbours complicate their situation and prolong the process of acceptance in children. However, the results of our interviews with five of their fathers still take on their role in parenting, even though it feels very difficult, it still has to be done.

Other studies have also revealed that the increased participation of fathers in childcare over the past few 
decades means fathers are also more involved in caring for children with disabilities. In the Chinese context, Huang et al. Pointed out the greater responsibility for children with disabilities that is borne by fathers in a patriarchal culture [26]. Al Yagon found that motherchild and father-son attachments influenced children's emotional development. However, mother-child attachment is associated with feelings of coherence while father-son attachment influences the child's hopes and efforts to live his life [27]. May and colleagues compared the effects of including fathers in programs for parents with children with intellectual disabilities [26], [28]. The child will be tighter if only the father or mother participated in the program. Emotionally, the bonding only happened to one father or mother.

Parenting a child with a disability can cause special problems. Children with special needs generally result in increased difficulties for their parents with life-long requirements and behaviour problems that often occur, of course, fathers with intellectual disabilities will experience many challenges but as long as the father accepts the presence of the child in his life, the father will be able to carry out his role as father completely. In the context of gender, fathers have been involved in parenting in addition to their traditional roles as breadwinners [29]. In the traditional role, the father can spend time with the children, and this includes tremendous progress because in the past the father only acted as the breadwinner and the care was completely left to the mother. This is one reason children are closer to their mother than their father.

Some dads reveal gradual changes in their role from breadwinner to caring for children is quite timeconsuming [30] especially when children fall ill, in their rage thoughts, will they be able to get through, am I able to take care of them? These questions are sometimes present to make dad stressed. But what is certain is that the presence of a father by the side of mother and child at the most difficult times is an essential unconditional acceptance that the father gives to his family. Fathers with children with special needs will have a strong and complete bond if from the start they have accepted the presence of children with special needs amid their family.

\section{CONCLUSION}

Fathers who accept children with intellectual disabilities will take their children to the right educational program, if they have other children will share the focus of parenting but the strongest focus on children with intellectual disabilities than other children. Refusal: a father who does not accept his child born with intellectual disabilities will harbour latent anger towards the disabled child so that the care becomes the mother's own without the father's participation in parenting. However, this will change after the father accepts the presence of children with special needs amid his family.

\section{ACKNOWLEDGMENTS}

Thanks to the fathers who are willing to be our respondents.

\section{REFERENCES}

[1] Bentley G. The up side of Down syndrome and fathering: An exploration of hope, satisfaction, and coping [Doctoral thesis, Texas Tech University]. Texas: TTU; 2011.

[2] Hobson L, Noyes J. Fatherhood and children with complex healthcare needs: qualitative study of fathering, caring and parenting. BMC nursing. 2011 Dec;10(1):1-3.

[3] Ware J, Raval H. A qualitative investigation of fathers' experiences of looking after a child with a life-limiting illness, in process and in retrospect. Clinical Child Psychology and Psychiatry. 2007;12(4):549-65.

[4] Chin R, Hall P, Daiches A. Fathers' experiences of their transition to fatherhood: a metasynthesis. Journal of Reproductive and Infant Psychology. 2011;29(1):4-18

[5] Davys D, Mitchell D, Martin R. Fathers of people with intellectual disability: A review of the literature. Journal of Intellectual Disability. 2017;21(2):175-96.

[6] Miller T. Falling back into Gender? Men's Narratives and Practices around First-time Fatherhood. Sociology [Internet]. 2011;45(6):10941109. Available from: http://soc.sagepub.com DOI:10.1177/0038038511419180.

[7] Burnard P. Teaching the analysis of textual data: An experiential approach. Nurse Education Today. 1996;16(4):278-81.

[8] Burnard P. The telephone interview as a data collection method. Nurse Education Today. 1994;14(1):67-72.

[9] Burnard P, Gill P, Stewart K, Treasure E, Chadwick B. Analysing and presenting qualitative data. British Dental Journal. 2008;204(8):429-32.

[10] Kaytez N, Durualp E, Kadan G. Engelli çocuğu olan ailelerin gereksinimlerinin ve stres düzeylerinin incelenmesi. Eğitim ve Öğretim Araştırmaları Dergisi. 2015;4(1):197-14.

[11]Deniz ME, Dilmaç B, Arıcak OT. An analysis of life satisfaction and state-trait anxiety of the parents with handicapped children. International Journal of Humanity Science. 2009;6(1):953-68. 
[12] Marsh L, Warren PL, Savage E. "Something was wrong": A narrative inquiry of becoming a father of a child with an intellectual disability in Ireland. British Journal of Learning Disability. 2018;46(4):216-24.

[13] Giallo R, Seymour M, Matthews J, Gavidia-Payne S, Hudson A, Cameron C. Risk factors associated with the mental health of fathers of children with an intellectual disability in Australia. Journal of Intellectual Disability Research. 2015 Mar;59(3):193-207.

[14]Beestin L, Hugh-Jones S, Gough B. The impact of maternal postnatal depression on men and their ways of fathering: an interpretative phenomenological analysis. Psychology \& health. 2014 Jun 3;29(6):717-35.

[15] Wieder S, Greenspan S. Can children with autism master the core deficits and become empathetic, creative, and reflective? Presented at the National Conference of the Interdisciplinary Council for Developmental and Learning Disorders 2004 Nov. 2005;9(November 2004):1-29.

[16]Efilti E. Examination to rejection behaviors of fathers having with mentally disabled child. Mehmet Akif Ersoy Üniversitesi Eğitim Fakültesi Derg. 2016;1(40):457-68.

[17] Goldscheider F, Bernhardt E, Lappegård T. Studies of Men's Involvement in the Family-Part 1: Introduction. Journal of Family Issues. 2014;35(7):879-90. DOI:10.1177/0192513X14522 237.

[18]Allen S, Daly KJ. The effects of father involvement. An Updated Research Sum. 2007 May;(603):1-27.

[19] Hendriyani, Hollander E, d'Haenens L, Beentjes JW. Children's media use in Indonesia. Asian Journal of Communication. 2012 Jun 1;22(3):30419.

[20]Bronte-Tinkew J, Scott ME, Lilja E. Single custodial fathers' involvement and parenting: Implications for outcomes in emerging adulthood. Journal of Marriage and Family. 2010 Oct;72(5):1107-27.

[21] Mitchell JL, Lashewicz B. Generative fathering: a framework for enriching understandings of fathers raising children who have disability diagnoses. Journal of Family Studies. 2019;25(2):184-98.

[22] Thackeray LA, Eatough V. 'Shutting the world out': an interpretative phenomenological analysis exploring the paternal experience of parenting a young adult with a developmental disability. Journal of Applied Research in Intellectual Disabilities. 2018;31:179-90.
[23] Martins CD, Walker SP, Fouché P. Fathering a child with autism spectrum disorder: An Interpretative Phenomenological Analysis. IndoPacific Journal Phenomenol. 2013;13(1):1-19.

[24]Heiman T. Parents of children with disabilities: Resilience, coping, and future expectations. Journal of developmental and physical disabilities. 2002 Jun;14(2):159-71.

[25] Garfield CF, Duncan G, Rutsohn J, McDade TW, Adam EK, Coley RL, Chase-Lansdale PL. A longitudinal study of paternal mental health during transition to fatherhood as young adults. Pediatrics. 2014 May 1;133(5):836-43.

[26]Huang YP, Tsai SW, Kellett U. Fathers of children with disabilities: Encounters with health professionals in a Chinese context. Journal of clinical nursing. 2012;21(1-2):198-6.

[27]Al-Yagon M. Fathers' emotional resources and children's socioemotional and behavioral adjustment among children with learning disabilities. Journal of Child and Family Studies. 2011 Oct;20(5):569-84.

[28]Zucker, SH. Education and Training and Autism in Developmental Disabilities. 2017; 52(3):1-16.

[29] McGill BS. Navigating new norms of involved fatherhood: Employment, fathering attitudes, and father involvement. Journal of Family Issues. 2014 Jun;35(8):1089-6.

[30] Craig L, Mullan K. How mothers and fathers share childcare: A cross-national time-use comparison. American sociological review. 2011 Dec;76(6):83461. DOI: $10.1177 / 000312241142767$. 